\title{
SURGE UMA NOVA ONG: AÇÃO EDUCATIVA
}

Ação Educativa surgiu com o objetivo de contribuir para que a educação possa servir aos interesses reconhecidos e proclamados pela maioria da sociedade. Por meio de uma ação cultural, trabalha para a construção e a consolidação de atores sociais no âmbito da sociedade civil pois somente numa sociedade forte, onde os segmentos têm capacidade e canais de expressão, pode existir um Estado democrático.

Ação Educativa nasce da experiência de trabalho com educação desenvolvida dentro do CEDI - Centro Ecumênico de Documentação e Informação, somada às experiências diversas de novos parceiros que se unem comungando objetivos e esperanças.

\section{ANTECEDENTES}

No Brasil e na América Latina, nos últimos 30 anos, trabalhos de Educação Popular (EP) foram marcantes e cunharam uma linha própria de atuação na área educacional.

Durante os anos 40 e 50 o conceito esteve referido aos sistemas públicos de ensino que se abriam aos setores populares, respondendo a necessidades impostas pelos processos de crescente industrialização e urbanização.

\section{O AUTOR}

Sérgio Haddad

Secretário executivo de Ação Educativa e Professor do Programa de Pós-Graduação em Educação da PUC/SP.
No contexto do populismo, EP esteve identificada com os movimentos de cultura popular desenvolvidos a partir de setores universitários e das igrejas. Valorizava a produção e reprodução simbólica de valores e comportamentos dos grupos populares a partir das suas manifestações religiosas, de lazer, trabalho, enfim, de todos os aspectos do seu cotidiano. A EP resgatava valores nacionais em uma conjuntura de pressão por internacionalizar a economia brasileira.

Durante o período em que os militares se mantiveram no poder, a partir de 1964 , EP passou a ser entendida como toda prática educativa que se voltasse à reconstrução do tecido social rompido pela ditadura. Foram práticas que se desenvolveram no âmbito da sociedade civil, entre os mais empobrecidos, e que buscavam a organização destes setores, a sua mobilização e conscientização, visando à transformação das suas condições de vida.

Assim, EP estava referida a toda prática educativa que lutava por melhores condições de existência, mais e melhores condições de trabalho, habitação, transporte, terra, saúde, moradia, educação, respeito aos direitos humanos, contra a discriminação de raça e gênero.

É neste contexto que nasceu o CEDICentro Ecumênico de Documentação e Informação, unindo, na composição de seus quadros, cristãos comprometidos com as Igrejas, setores de Igrejas que faziam sua opção pelo trabalho pastoral popular e um 
grupo de intelectuais preocupados com a educação, que vinham de outras práticas de resistência ao regime militar, comungando valores comuns. O CEDI nasce como uma instituição de educação popular realizando um trabalho de comunicação e informação sobre direitos humanos nas diversas pastorais sociais, particularmente as católicas, principais espaços de resistência aos desmandos do regime militar.

Com o processo de democratização, novos desafios se impuseram aos que se denominavam educadores populares. Outros atores sociais surgiam - os sindicatos, as organizações populares nos setores urbanos e rurais, novos partidos políti$\cos$ - ampliando as possibilidades de reconstrução do tecido social. O Estado deixou de ser o adversário principal da EP. Em alguns momentos os próprios educadores populares vieram a ocupar cargos na administração púb̨lica, discutindo a possibilidade de uma EP a partir destes espaços. A democratização do nosso país veio acompanhada de uma série de questionamentos aos modelos paradigmáticos que influenciaram a EP na luta por uma nova sociedade. O discurso revolucionário é substituído pelo da construção de uma sociedade com valores democráticos, com justiça social e, mais recentemente, com desenvolvimento sustentável.

Neste lento processo de redemocratização da sociedade brasileira, o CEDI procurou se reorganizar internamente, criando programas de trabalho que uniam documentação, informação e assessoria a determinados setores da sociedade, visando à qualificação dos seus serviços e a uma inserção mais dinâmica nos diferentes espaços sociais onde atuava. Acompanhando o movimento social, ampliou o espectro de atuação para outros setores da sociedade brasileira, não mais se restringindo ao espaço pastoral. Passava-se de uma fase de resistência a um período propositivo e de apoio aos movi- mentos sociais e setores da sociedade civil que se institucionalizavam.

Esta nova conjuntura permitiu ainda que se redefinissem, no âmbito da prática política geral, as práticas que eram especificamente educacionais. Foi neste ŕ́nomento que se organizou, dentro do CEDI, o Programa Educação e Escolarização Popular (EEP), que passou a articular atividades especializadas de documentação, pesquisa, reflexão teórica, assessoria à implantação de programas educativos, a movimentos populares, constituição de redes, formação de educadores e produção de materiais educativos.

Neste contexto de redemocratização, EEP uniu o ideário da EP à problemática da educação básica. Apoiou processos de luta e participação popular na ampliação e qualificação dos serviços educacionais; apoiou práticas educativas escolares destes setores sociais.

Em 1994, o CEDI, depois de um longo processo de avaliação, tomou a decisão de superar sua forma institucional, encerrando suas atividades, dando lugar a novas organizações sucessoras. Avaliou-se que o grau de qualificação e dinamismo de cada um dos seus programas produziu uma complexidade institucional muitas vezes difícil de gerir.

Considerou-se que, diante dos enormes desafios colocados pela conjuntura nacional e internacional, o mandato do CEDI poderia ser cumprido mais eficazmente por entidades autônomas que pudessem continuar o processo de qualificação de seus serviços.

Como conseqüência desta organização, em 1994, com a aprovação da Assembléia do CEDI, foi criada Ação Educativa - Assessoria, Pesquisa e Informação assim como outras três novas entidades. 


\section{O QUE FAZ AÇÃO EDUCATIVA?}

A partir de uma rigorosa análise da conjuntura brasileira, da experiência acumulada nos 20 anos de trabalho do CEDI junto com idéias, valores e experiências dos novos sócios que se incorporaram, definiuse como objetivo geral desta nova ONG promover ações educativas e estimular o envolvimento da sociedade com a questão educacional, tendo em vista a construção da democracia (no âmbito da sociedade e do Estado), a promoção da justiça social e do desenvolvimento sustentável.

Para a realização deste objetivo geral, Ação Educativa entende como estratégico contribuir para a redefinição das finalidades da educação e de seus parâmetros de qualidade, além de propor e desenvolver alternativas para democratização da educação diante do contexto de crise econômica, social e do Estado na América Latina.

Ação Educativa trabalha referenciada aos valores e às práticas do amplo movimento de educação e cultura popular e à tradição de luta e defesa da sociedade brasileira por um ensino público de qualidade e que atenda a todos.

Portanto, está voltada aos setores populares, articulando objetivos educacionais e políticos; considera o educando como ator do processo educacional e reconhece seus valores culturais no processo educativo; relaciona-se com os movimentos populares e sociais, fortalecendo a sociedade civil, mesmo quando esta educação é realizada a partir do Estado.

Um traço característico herdado das intervenções do CEDI é a prioridade conferida aos processos educativos com jovens $\mathrm{e}$ adultos. Parte dessa opção nasce da tradição histórica de associação entre educação popular e de adultos na América Latina, bem como da influência exercida pelas idéias e práticas de Paulo Freire na América Latina e na África.

Decorre, também, e principalmente, de uma interpretação político-sociológica que atribui à educação de jovens e adultos um papel importante na estratégia de (re)construção democrática da sociedade brasileira, ademais de ser a educação um instrumento simultaneamente condicionado e condicionante do exercício da cidadania plena e da democracia.

Outro traço característico da atuação do CEDI, no qual a Ação Educativa se apóia, é a aposta no papel das organizações autônomas dos sujeitos sociais na construção de uma sociedade democrática e na valorização da sociedade civil como espaço privilegiado de trabalho. Tem como interlocutores principais as redes e organizações de educação popular, as associações técnico-científicas, as igrejas, os sindicatos de trabalhadores, os centros de pesquisa, os partidos políticos, os meios de comunicação de massa, as agências de cooperação, os movimentos e grupos populares, particularmente aqueles ligados a trabalhos com educação de jovens e adultos.

Finalmente, a nova ONG procura integrar a reflexão e a prática especificamente educacionais no âmbito da discussão e proposição de orientações político-culturais gerais para a sociedade, derivada dos valores ecumênicos do CEDI, particularmente no que diz respeito à democracia, à paz, à defesa da vida e do ambiente, aos direitos das minorias e ao reconhecimento do caráter multi-étnico da sociedade brasileira.

\section{COMO TRABALHA AÇÃO EDUCATIVA?}

Ação Educativa realiza documentação, produz e veicula informações, desenvolve pesquisas, presta assessoria, capacita educadores e elabora materiais educativos. 
Subsidia organizações da sociedade civil e a população em geral com dados, informações e argumentos para o exercício de pressões sobre o Estado, a fim de que cumpra com suas obrigações constitucionais na área da educação básica.

Também apóia organizações da sociedade civil na definição de exigências e critérios quanto à elaboração de currículos e programas de formação de educadores, bem como de mecanismos de avaliação e controle de seu desempenho.

Presta serviços e implanta projetos junto a setores da sociedade civil e a órgãos públicos, na perspectiva de efeitos-demonstração, impacto e multiplicação.

Desenvolve meios e procedimentos de informação e comunicação qualificada, junto a setores específicos e à opinião pública, através de veículos próprios, redes e/ou pelos meios de comunicação de massa. Além disso, fomenta e participa de lobbies, campanhas, ações judiciais visando à garantia $\mathrm{e}$ efetivação dos direitos sociais, particularmente os educacionais.

Para desenvolver o seu trabalho, Ação Educativa entende como fundamental construir interfaces entre os setores da sociedade civil (movimentos populares, so- ciais, sindicais, pastorais etc.), setores estatais (governos federal, estadual, municipal, legislativo, executivo e judiciário) e setores produtores de conhecimentos (universidades e centros de pesquisa). $\mathrm{O}$ equilíbrio de relacionamento com cada um destes setores, de maneira autônoma e independente, é o que permite o desenvolvimento das atividades de assessoria, produção de conhecimento, comunicação e informação de maneira qualificada e com eficiência.

Ação Educativa trabalha nos planos lo$\mathrm{cal}$, regional e nacional. No plano local, a escolha das intervenções se faz prioritariamente tomando-se como critério o caráter paradigmático destas ações. No plano regional e nacional, os critérios fundamentais recaem sobre os aspectos impacto e advocacy (apoio).

No desenvolvimento dos seus trabalhos, Ação Educativa procura manter a unidade entre os planos do político, das competências técnicas e dos valores culturais e éticos.

Ação Educativa está aberta a todos os interessados. Contatos:

Av. Higienópolis, 901 - São Paulo-SP

CEP 01238-001

FONE: (011) 825.5544

FAX: (011) 825.7861 